\title{
Finite Element modeling of an orthotropic laminated plate under cylindrical bending
}

\author{
J. S. Kalyana Rama ${ }^{1}$, B. Panduranga Rao ${ }^{2}$, K. Mohan Rao ${ }^{3}$ \\ ${ }^{1,2}$ Civil Engineering Department, ${ }^{3}$ Mechanical Engineering Departments, V. R. Siddhartha Engineering \\ College, Vijayawada-520007, Andhra Pradesh, India
}

\begin{abstract}
Assumption of plane strain is valid for the structures made of isotropic and specially orthotropic materials. In case of generally orthotropic structure though the geometry, constraints and loading are symmetrical, the material arrangement may not permit to consider as a $2 D$ plane strain problem such as an angle-ply laminate where the fibers are oriented in the plane of the plate. In such cases $3 D$ analysis is required. However when the third dimension is infinitely long, the problem can be modeled with a finite length plate without losing the accuracy of the result. The present investigation deals with the identification of minimum length required to model an infinitely long FRP laminated plate under cylindrical bending with two different end conditions subjected to uniform pressure using three-dimensional finite element analysis. A four-layered angle-ply laminate with symmetric and anti-symmetric arrangement is modeled in ANSYS software and the required length for two different thickness ratios $(S=10$, and 50) is determined based on the variation of transverse deflection and in-plane normal stress along the span direction of the plate.
\end{abstract}

Keywords:, cylindrical bending, Finite element analysis, laminated plates, Orthotropic

\section{Introduction}

A composite is a structural material that consists of two or more combined constituents that are combined at a macroscopic level and are not soluble in each other. One constituent is called the reinforcing phase and the one in which the fiber is embedded is called the matrix. The reinforcing phase material may be in the form of fibers, particles, or flakes. The matrix phase materials are generally continuous. Examples of composite systems include concrete reinforced with steel and epoxy reinforced with graphite fibers, etc.

[Pagano, 1969] studied about the limitations of classical laminated plate theory comparing with the solutions of several specific boundary value problems to the corresponding theory of elasticity solutions. $\mathrm{He}$ concluded that conventional plate theory leads to a very poor description of laminate response at low span to depth ratio but converges to the exact solution as this ratio increases. This is also valid in the study of sandwich plate under cylindrical bending for unidirectional laminate. [Pagano, 1970] extended his study of cylindrical bending to a bidirectional laminate i.e. cross ply laminate $(0,90)$, which further extended to the behavior of a rectangular plate pinned on all four edges. He [Pagano, 1970] further refined his study on cylindrical bending of plates considering the influence of shear coupling. He formulated three-dimensional elasticity solution for the static bending of composite laminates in which the axes of elastic symmetry of the various layers are parallel to the plate axes. He also considered that the state of plane strain cannot exist under the general conditions of material symmetry which was already discussed by [Lehknitskii, 1963]. [Kerr, 1968] proposed Extended Kantorovich Method (EKM) for 2D elasticity problems which further extended to 3D elasticity problem for a transversely loaded angle-ply laminate in cylindrical bending. [Lo et al, 1977], studied the deformation of homogeneous and laminated plates using higher order theory of plates. [Reddy J N, 1984] simplified the complexity of the study of plates by [Lo et al, 1977]. [Kant and Swaminathan, 2001], in their paper concluded that the higher order refined theory gives better results over solutions obtained by first order and higher order theories considered. [Xiao-ping Shu and Kostas Soldatos, 2000] worked on Cylindrical bending of laminated plates subjected to different sets of edge boundary conditions and evaluated detailed stress distribution. [Ren, 1987] using Fourier series analyzed the deformation of simply supported anti-symmetrical angle-ply laminated plate under transverse loading and results are compared with Classical laminated plate theory and Mindlin theory. [Brett Arnold Pauer, 1993] in his MS thesis developed a finite element program for the analysis of laminated composite plates using first order shear deformation theory and studied the elastic behavior of plate and small deflections due to the application of the loads. [Kam Chee Zhou, 2011] from University of Malaysia submitted his thesis on Finite element formulation for composite laminates. This study investigated the effect of perfect and imperfect bonding on mechanical behavior of two layered cross-ply composite laminate. Very recently, using EKM [Santosh Kapuria and Poonam Kumari, 2011] obtained a solution of laminated composite plate in cylindrical bending.

From the study of literature on cylindrical bending of FRP laminates, the work for the analysis of infinitely long FRP laminate under cylindrical bending using three-dimensional finite element method is carried 
out with an intention to ensure the application of this method for the said analysis, so that at later stage, the method can be extended to analyze the structures with geometric imperfections and other complexities in material, loading and constraints where the classical tools fail to yield closed form solution. The objective of the present investigation is to simulate the behavior of an infinitely long generally orthotropic laminate under cylindrical bending subjected to uniform transverse pressure using 3D finite element analysis.

\section{Problem Modeling}

A four-layered orthotropic laminate shown in Fig. 1 is modeled using ANSYS software. The dimensions of the plate are taken as $\mathrm{X}=50 \mathrm{~mm}$, Y varying from $50 \mathrm{~mm}$ to $300 \mathrm{~mm}$ with an increment of $50 \mathrm{~mm}$ and for two different values of $\mathrm{Z}$ i.e. $1 \mathrm{~mm}(\mathrm{~S}=50)$ and $5 \mathrm{~mm}(\mathrm{~S}=10)$. Symmetric $(\theta /-\theta /-\theta / \theta)$ and Antisymmetric $(\theta /-\theta / \theta /-\theta)$ orientations are used as a stacking sequence in the plate. The element used for the present analysis is SOLID 95 of ANSYS software which is based on three-dimensional elasticity theory and is defined by 20 nodes having three degrees of freedom at each node, translation in node $\mathrm{x}, \mathrm{y}$ and $\mathrm{z}$ directions. The properties of the constituent materials used for the present analysis are given in Table 1.The plate is hinged on both the sides parallel to $\mathrm{Y}$-axis and is subjected to uniform transverse pressure of $1 \mathrm{MPa}$.

Table 1: Material Properties [Balakrishna Murthy V, 2005]

\begin{tabular}{llll}
\hline Material & $\mathrm{E}(\mathrm{GPa})$ & $\mathrm{v}$ & $\mathrm{G}(\mathrm{GPa})$ \\
Graphite-epoxy & $\mathrm{E}_{1}=141.6764$ & $\mathrm{v}_{12}=0.257$ & $\mathrm{G}_{12}=4.03$ \\
& $\mathrm{E}_{2}=12.386$ & $\mathrm{v}_{13}=0.4206$ & $\mathrm{G}_{13}=4.3592$ \\
& $\mathrm{E}_{3}=12.386$ & $\mathrm{v}_{23}=0.257$ & $\mathrm{G}_{23}=4.03$
\end{tabular}
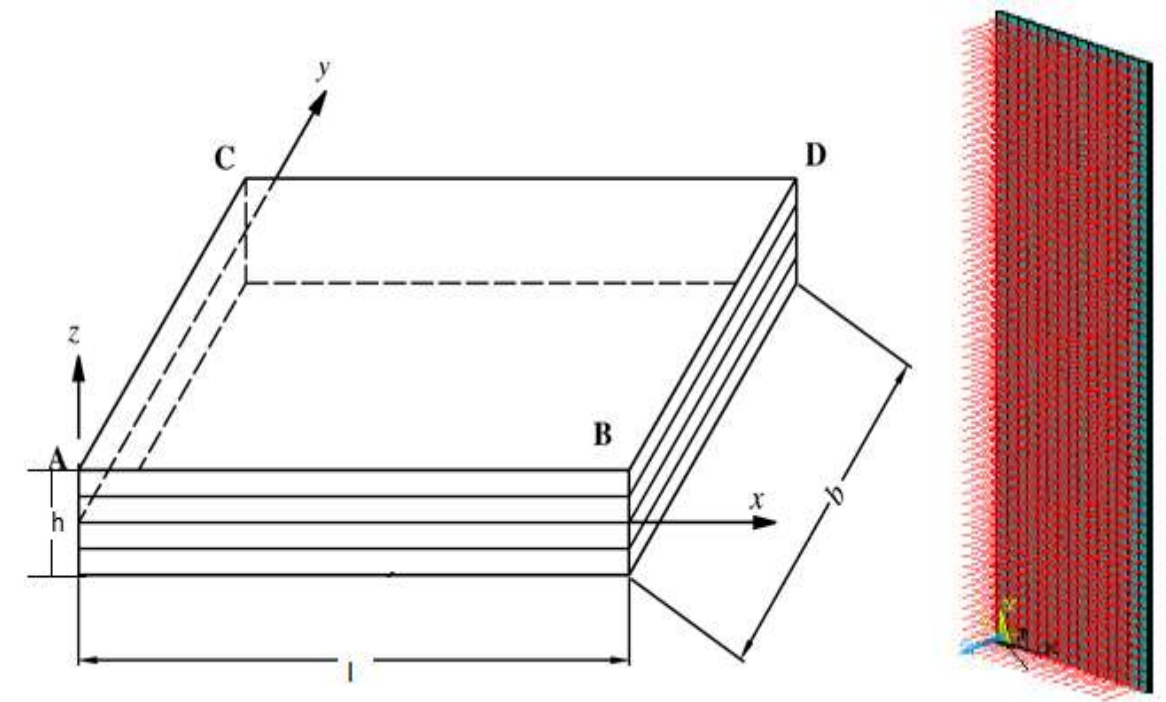

Figure 1(a) Four-layered orthotropic laminate and 1(b) finite element model with Uniform pressure

\section{Results And Discussion}

Figures 2 to 9 shows the plot between Stress, deflection and length of the plate for different fiber orientations with thickness ratios 50 and 10. From the graphs it is observed that with the increase in length, the stress as well as deflection decreases and remains constant after a particular length. These results indicates that the stress and deflection remains constant from a length equal to $250 \mathrm{~mm}$ which clearly implies that for an infinitely long FRP laminated plate under cylindrical bending the finite length of $250 \mathrm{~mm}$ would be sufficient for analysis. For a thickness ratio equal to 50 and 10, there is a slight drop down of the values of stress and deflection when the lengths increase from $50 \mathrm{~mm}$ to $100 \mathrm{~mm}$, on further increase in length to $300 \mathrm{~mm}$ the rate of decrease is small. The reason behind the reduction of stresses and deflection with the increase in the length is due to the presence of anticlastic curvature of the plate which decreases with increase in length of the plate and theoretically negligible for an infinitely long plate 


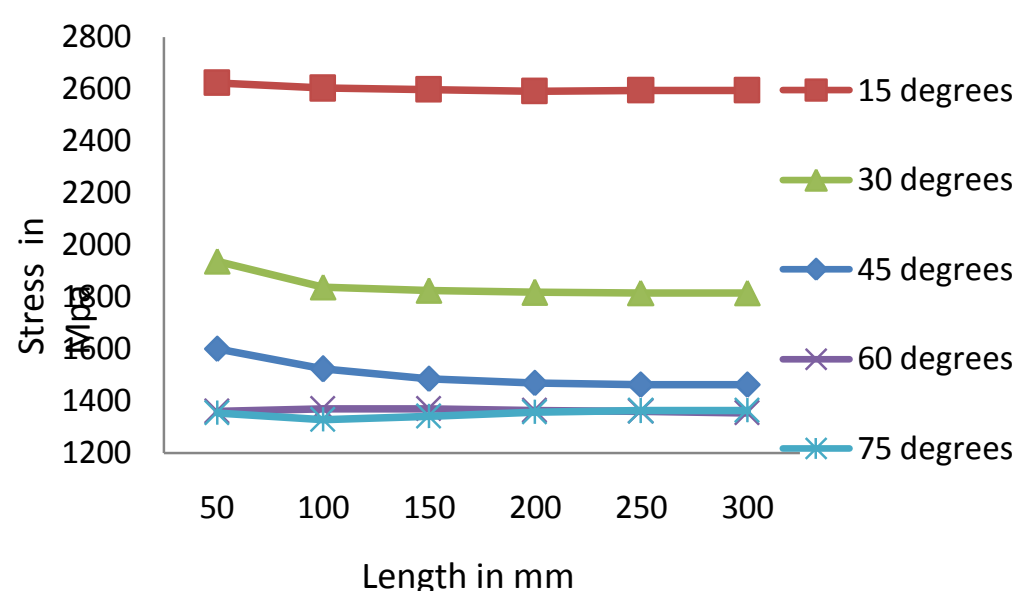

Figure 2 Length Vs Stress for a Hinged-Hinged support for $\mathrm{S}=\mathbf{5 0}$

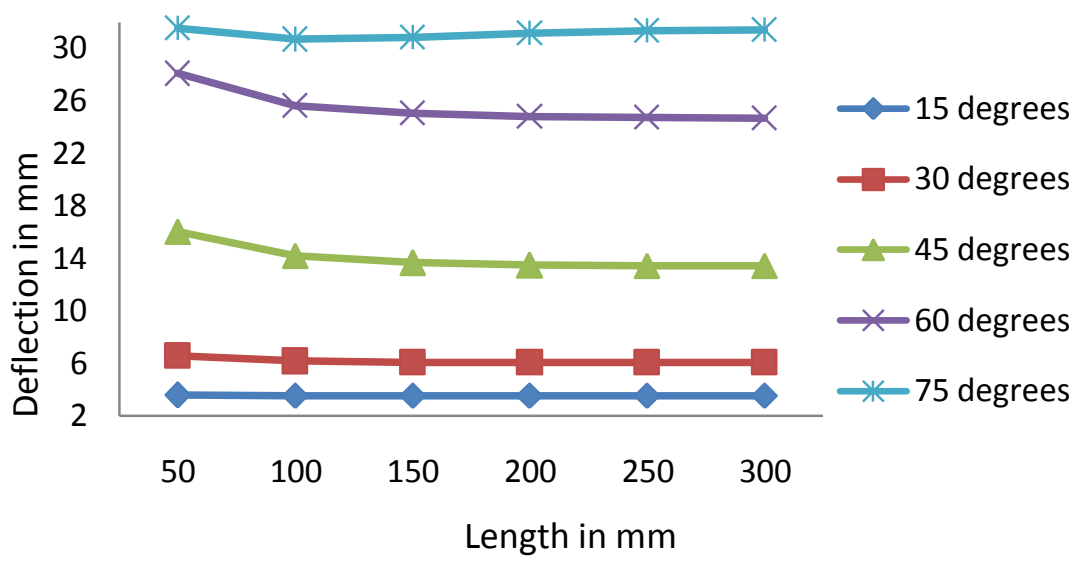

Figure 3 Length Vs Deflection for a Hinged-Hinged support for $\mathbf{S}=\mathbf{5 0}$

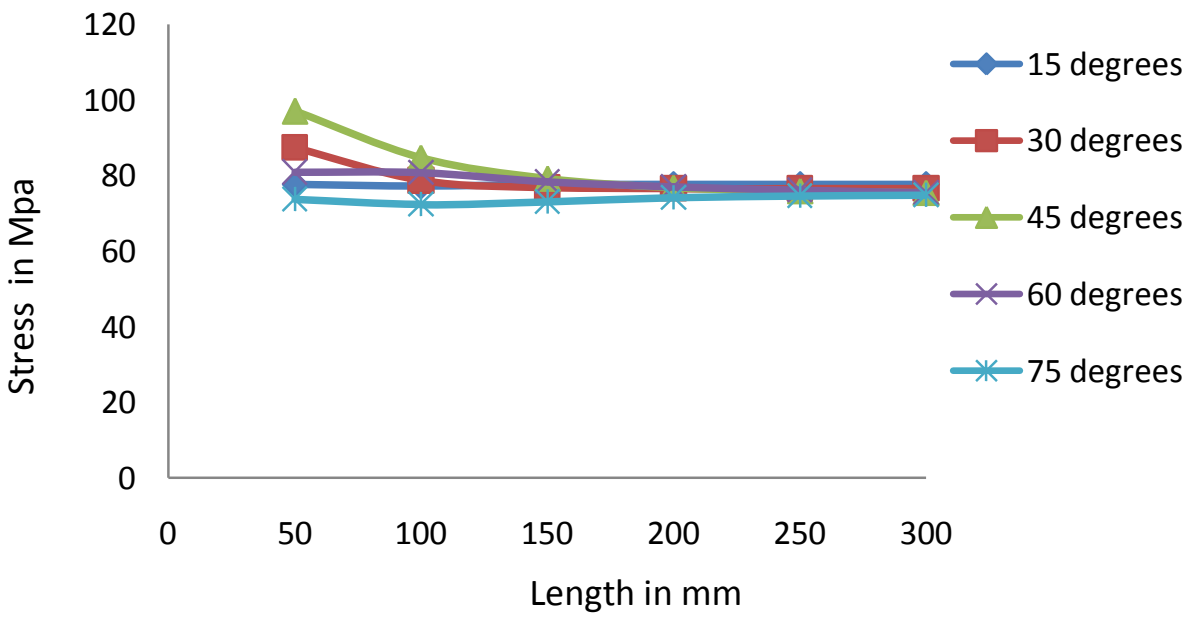

Figure 4 Length Vs Stress for a Hinged-Hinged support for $S=10$ 


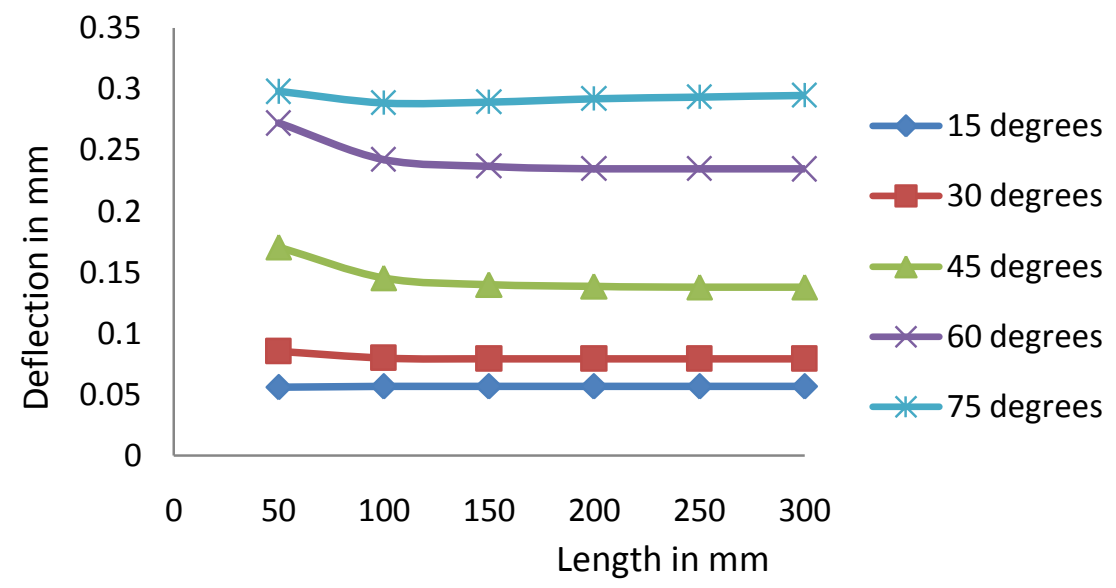

Figure 5 Length Vs Deflection for a Hinged-Hinged support for $\mathrm{S}=10$

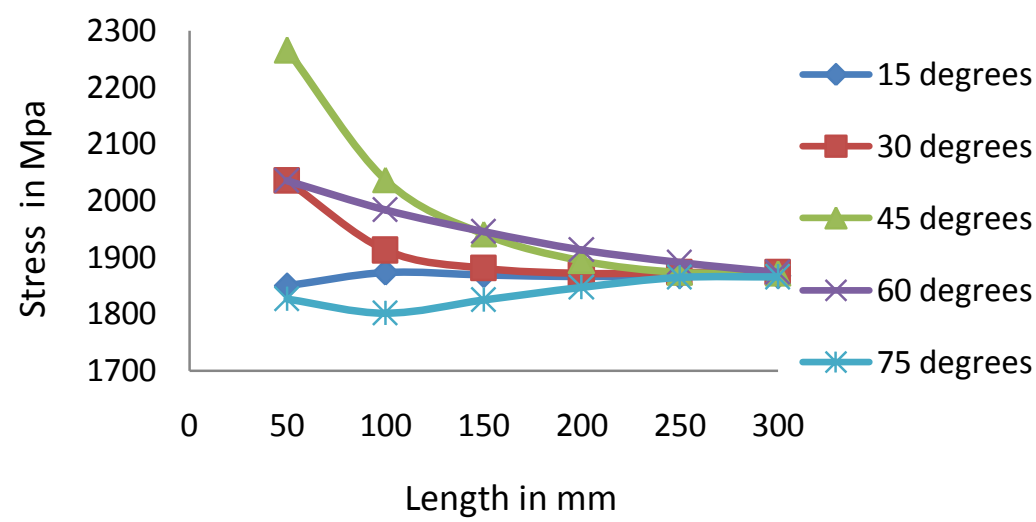

Figure 6 Length Vs Stress for a Hinged-Roller support for $\mathrm{S}=\mathbf{5 0}$

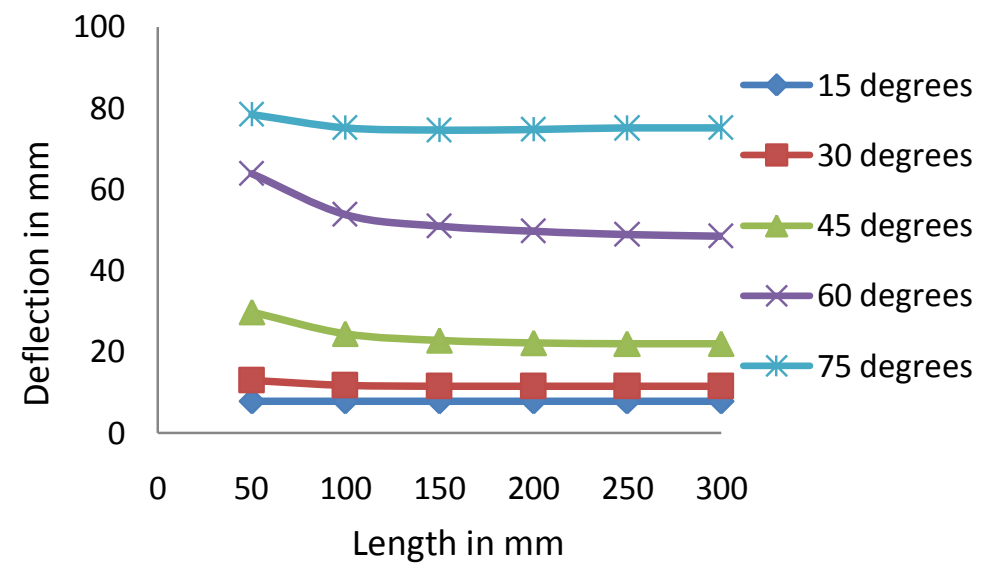

Figure 7 Length Vs Deflection for a Hinged-Roller support for $\mathrm{S}=\mathbf{5 0}$ 


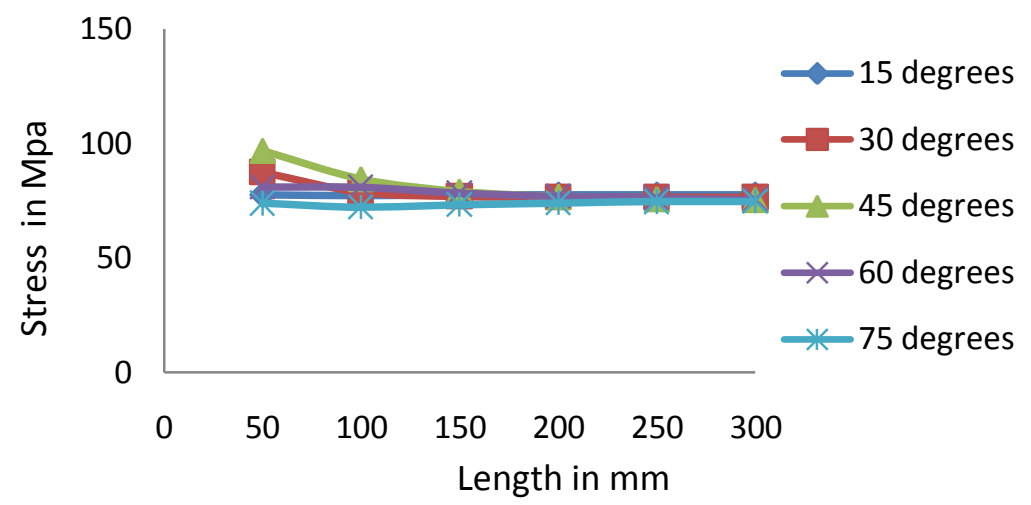

Figure 8 Length Vs Stress for a Hinged-Roller support for $S=10$

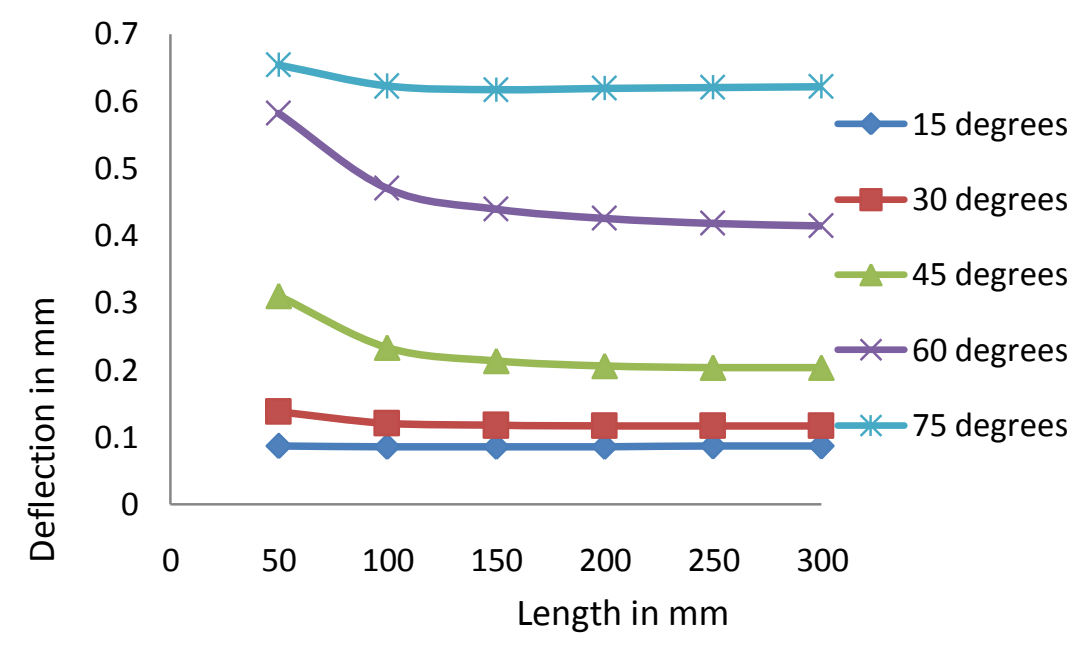

Figure 9 Length Vs Stress for a Hinged-Roller support for $\mathbf{S}=10$

Figures 10 to 13 show the percentage variation in deflection and bending stress between the two successive lengths of the plate for different fiber orientations. It is observed that after reaching a length of $250 \mathrm{~mm}$, the percentage variation reaches to zero. Hence a length of $250 \mathrm{~mm}$ may be recommended to analyze infinite plate of the type considered in the present analysis.

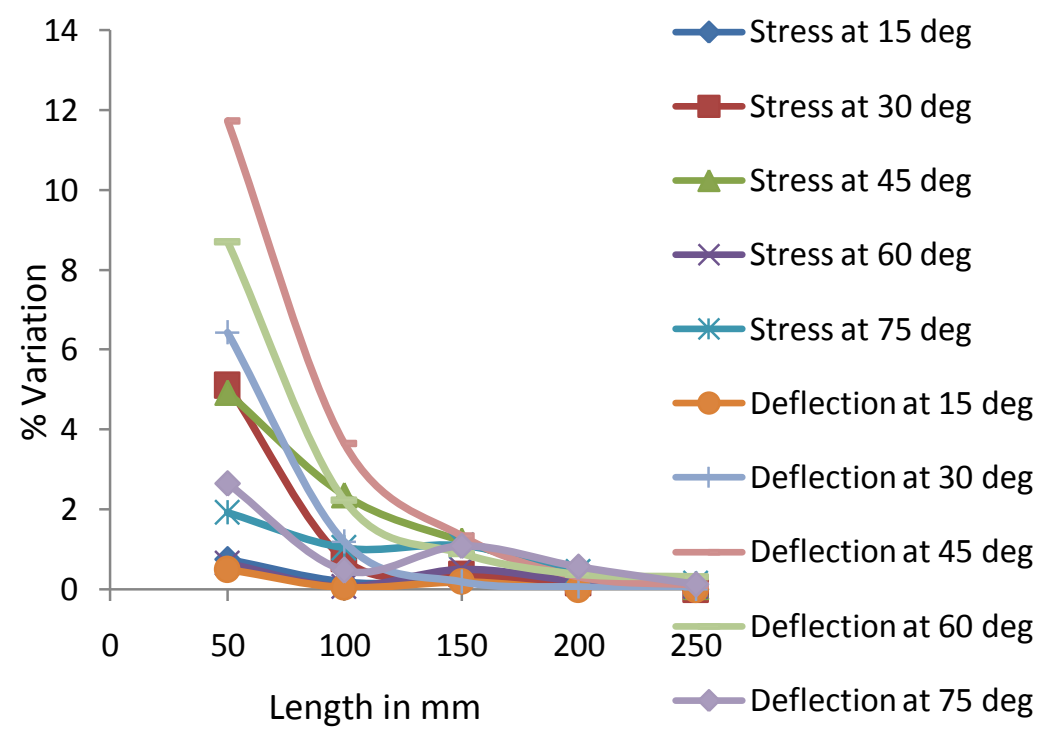

Figure 10 Change in \% Variation of stress and deflection with respect to Length of the hinged-hinged plate for $\mathbf{S}=\mathbf{5 0}$ 


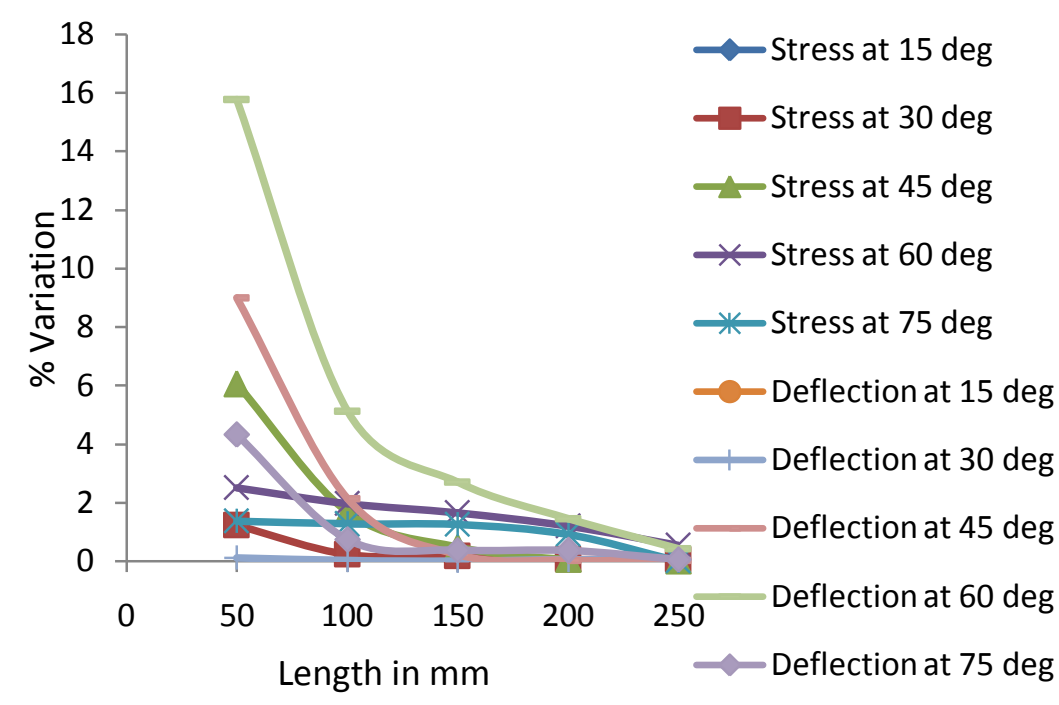

Figure 11 Change in \% Variation of stress and deflection with respect to Length of the hinged-roller plate for $\mathrm{S}=\mathbf{5 0}$

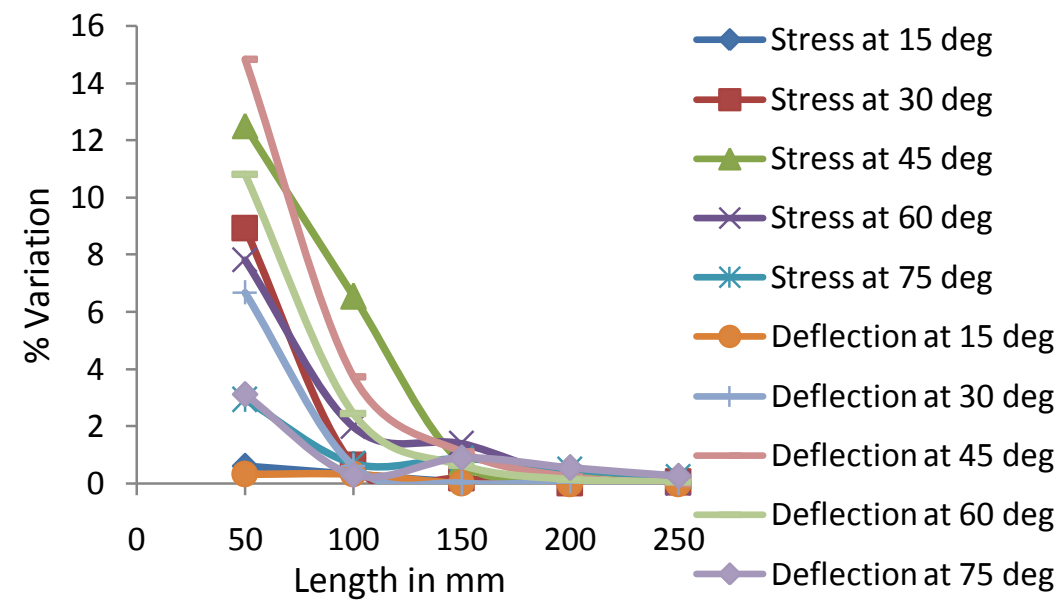

Figure 12 Change in \% Variation of stress and deflection with respect to Length of the hinged-hinged plate for $S=10$

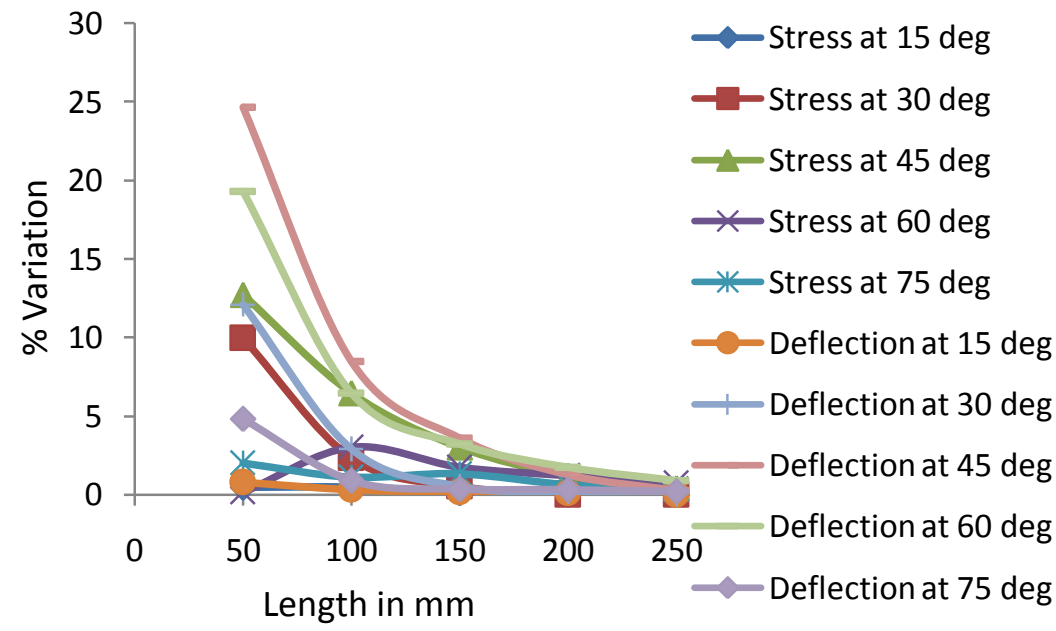

Figure 13 Change in \% Variation of stress and deflection with respect to Length of the hinged-roller plate for $S=10$ 


\section{Conclusions} were made.

From the analysis of a four-layered laminated plate under cylindrical bending following conclusions a) Angle-ply laminated plates can be analyzed only using three-dimensional analysis because two-dimensional analysis failed to deal with shear-coupling effects.

b) A length of $250 \mathrm{~mm}$ is sufficient to analyze a graphite-epoxy laminated plate with four layers of symmetric and anti-symmetric fibers for two different edge conditions with two thickness ratios.

c) With the increase in thickness ratio the deflections will be increased as the thinner plates produce large deflections.

d) This approach reduces the computational time while analyzing an infinite plate with above said material properties.

e) Finite element approach in gives better results for a long orthotropic angle-ply laminate as it handles the fibers oriented in different angles compared to that of conventional methods.

\section{References}

[1]. Pagano N.J., Exact solutions for composite Laminates in Cylindrical Bending, Journal of Composite Materials Vol.3 (1969), p. 398.

[2]. Pagano N.J., Exact solutions for Rectangular Bidirectional Composites and Sandwich Plates, Journal of Composite Materials Vol.4 (1970), p. 20.

[3]. Pagano N.J., Influence of shear coupling in Cylindrical Bending of Anisotropic Plates, Journal of Composite Materials Vol.4 (1970), p. 330.

[4]. Lekhnitskii S.G., Theory of Elasticity of an Anisotropic Body, (Holden Day, 1963)

[5]. Kerr, A.D., An Extension of the Kantorovich Method, 1968, Q. Appl. Math., 4, pp. 219-229.

[6]. Lo K.H., Christensen R.M., and Wu E.M., A Higher Order Theory of Plate Deformation-Part 1: Homogeneous Plates, Journal of Applied Mechanics, 1977, volume 44.

[7]. Reddy J.N., A Simple Higher-Order Theory for Laminated Composite Plates, Journal of Applied Mechanics, 1984, volume 51.

[8]. Kant T., and Swaminathan K., Analytical solutions for the static analysis of laminated composite and sandwich plates based on a higher-order refined theory, Composite Structures 53, 2001, 73-85.

[9]. Xiao-Ping Shu, Kostas P. Soldatos, Cylindrical bending of angle-ply laminates subjected to different sets of edge boundary conditions, Int. J. Solids Struct., 37, 4289-4307, 2000.

[10]. Ren J.G., Bending of simply-supported anti-symmetrically laminated rectangular plate under transverse loading, Composites Science and Technology, Volume 28, Issue 3, 1987, pages 231-243.

[11]. Brett Arnold Pauer, Development of a finite element program for the analysis of laminated composite plates using first order shear deformation theory, MS Thesis, The Ohio State University, 1993.

[12]. Kam Chee Zhou, Finite element formulation for composite laminates, MS Thesis, University of Malaysia, 2011.

[13]. Santosh Kapuria and Poonam Kumari, Extended Kantorovich Method for Three-Dimensional elasticity solution of Laminated Composite structures in Cylindrical Bending, Journal of Applied Mechanics, ASME, November 2011, Vol.78/ 061004-1 to 0610048 .

[14]. Bala Krishna Murthy V., Analysis of Stresses around Cutouts in Skew Laminated Composite Plates, PhD Thesis, JNTU Hyderabad, 2005.

[15]. Ferdinand P. Beer, Russel Johnston E., John T.Dewolf, Mechanics of materials, (Tata McGraw Hill, Fourth edition, 2006).

[16]. ANSYS Reference Manuals, 2011.

[17]. Praveen K J V S, Analysis of cross-ply laminates under cylindrical bending using plane strain approach, COM 167, International Conference on Recent Advances in Mechanical Engineering 2012, Dr. 